\title{
THE IMMERSIVE ARTISTIC EXPERIENCE AND THE EXPLOITATION OF SPACE
}

\author{
Bonnie Mitchell \\ Digital Arts, School of Art \\ Bowling Green State University \\ Room 1000 Fine Art Center \\ Bowling Green, Ohio \\ USA \\ bonniem@bgsu.edu \\ http://immersiveinstallationart.com
}

Over the past fifty years, artists have explored the computer's potential to create both virtual and physical art forms that embrace the concept of space. Through the use of immersion, interaction, and manipulation of both virtual and physical space, computer artists have created powerful aesthetic environments that enable audiences to experience alternative realities. Immersive installations that respond the human body and online multi-user virtual environments such as Second Life satisfy the viewer's inherent desire to escape physical reality and become part of the art experience itself.

\section{INTRODUCTION}

We often think of physical space as a three dimensional entity that exists between objects. Although this entity may contain "nothing" but air, we conceive of it as physically definable, malleable, and constructible. We experience sensations in space and define our perception of the world by our relationship to space. This notion of "nothingness" attributed to space poses some interesting questions. Is space actually an entity, a relationship between our senses and physical objects, or an abstract concept? Can we define, create, and manipulate space to create aesthetic experiences?

Since the early 1950s, artists have explored the computer's potential to create both virtual and physical art forms that embraced the concept of space. [3] Because the technical complexities and limitations of digital technology inhibited the full realization of many ambitious concepts, a number of early innovative ideas' destiny was to remain "concept-only" in seminal papers and high-tech lab experiments. In 1968, Ivan Sutherland created a virtual reality system that gave the user the ability to occupy the same "space" as a computer generated wire-frame object. Through the use of a headmounted display, the user was able to interact with and manipulate the object. [13]

This revolutionary experiment paved the way for artists, such as Myron Krueger, who developed a series of art installations that strived to embrace and mimic real world interaction. Krueger coined the term "Artificial Reality" to describe a new genre of work in which the user's physical body influenced the unfolding of meaning in the work of art. From his earliest interactive artworks, "Glowflow" and "Videoplace" in 1969, to his experiments in the 90's with hand-gesture interfaces, Krueger strove to create responsive environments that used computer-mediated physical space to construct the aesthetic experience. [7] According to Noah Wardrip-Fruin, the art community at first 
rejected Krueger's work, possibly because it focused on "response" rather than the creation of aesthetic objects. During this same period, however, Allan Kaprow, an artist already accepted as a member of the fine art community received applause for his rejection of the physical object. [15]

\section{MIMICING THE REAL}

Both Krueger and Sutherland attempted to fabricate a "virtual" space that facilitated unique experiences unrealizable in the real world without computer assistance. Although this concept is often associated with Star Trek's holodeck, (first aired in Star Trek, The Animated Series from 1973-74), [10] science fiction writer Ray Bradbury first defined the potential of such a simulated space in The Veldt, a short story included in the The Illustrated Man, written in 1951. Set in a futuristic world where children live out their fantasies by imagining environments and events in the "nursery", this perfect world falls apart when the virtual becomes real. The story concludes when the parents are eaten by lions that the over-privileged, vengeful children conjure up in the nursery. [2] The division between fiction and reality is blurred creating the ultimate virtual world where anything is possible.

Fascination with constructed reality appears to be inherent in the human psyche. From the beginning of recorded history, humans have engaged in storytelling. Cave paintings, petroglyphs, ancient artifacts and rituals mirror our contemporary obsession with worlds that extend beyond our concrete physical environment. An inherent desire to experience that which transcends our physical confinement to limited environments, has resulted in the popularity of books, movies, television, video games, theatre, and other forms of escapism. When coupled with the ability to directly affect the outcome of the experience by utilizing our bodies as an interface, the constructed world comes closer to mimicking the real world. If one of early computer art's goals was to create worlds such as the nursery and holodeck, fifty years later we have still completely missed the mark. Although there are research projects and artistic endeavours that still seek to create virtual spaces indistinguishable from physically real spaces, new directions have emerged, spurred on by technical and philosophical issues resulting from past attempts to create such spaces.

\section{SENSORY IMMERSION}

Through their nascent efforts to create intelligent, holodeck-like spaces, artists and computer scientists have discovered that human perception of reality relies on a large, complex combination of factors. In the past fifty years, many of these factors were employed in a variety of ways to create aesthetic experiences that differ markedly from original attempts at virtual realism. The sensation of "being there" depends heavily upon sensory absorption within the environment. One must feel immersed in the space and physically a part of it. Sensory immersion is fundamental to our relationship with the natural environment.

Capitalizing on the psychological power of immersion, contemporary artists have created immersive spaces that enable the audience to escape to other realms and experience genuine emotional responses. The power of artistic illusion, as well as the human desire to create realities within realities, enables us to suspend our belief in our 
physically situated world and accept artificial constructs. Our obsession with video games, short stories and films demonstrates our desire to enter symbolic space and actively engage with alternate realities. In The Metaphysics of Virtual Reality, Michael Heim asks, "Are not all worlds symbolic? Including the one we naively refer to as the real world, which we read off with our physical senses?" [6]

\section{ENCUMBERED EXPERIENCES}

When discussing immersive worlds, we typically divide the experience into two categories: encumbered and non-encumbered. Although the initial concept of holodecklike virtual reality involved the ability to fully interact with the space, and all entities within it, using our body and mind as primary input devices, computer scientists and artists still cannot technically implement such an ambitious ideal. Early technological developments such as Sutherland's head-mounted display in the 1960s, M.I.T.'s Aspen Movie Map in the 1970s (Fig. 1), NASA Ames' Virtual Environment Workstation Project which included auditory, speech and gesture interaction and VPL's Dataglove in the 1980s, all paved the way for artists to begin to explore creative uses of computersimulated spaces that transcended the desire to perfectly replicate realistic sensory environments. [5] Aesthetic concerns that focused on the involvement of the participant and creative exploration of concepts became key in the development a series of seminal works. In 1995, at the Ricco-Maresca Gallery in New York, Char Davies exhibited Osmose (Fig. 2) as part of the Code exhibition (a seminal exhibition of innovative computer art). Participants were outfitted with a head-mounted display and motion/breath sensitive vest that enabled them to enter a world unlike any they had experienced before. Abandoning realistic visuals and interaction in favour of abstraction and sensory body involvement, Davies' work facilitated a unique "perception of consciousness: a feeling of disembodiment and embodiment at same time". [4]

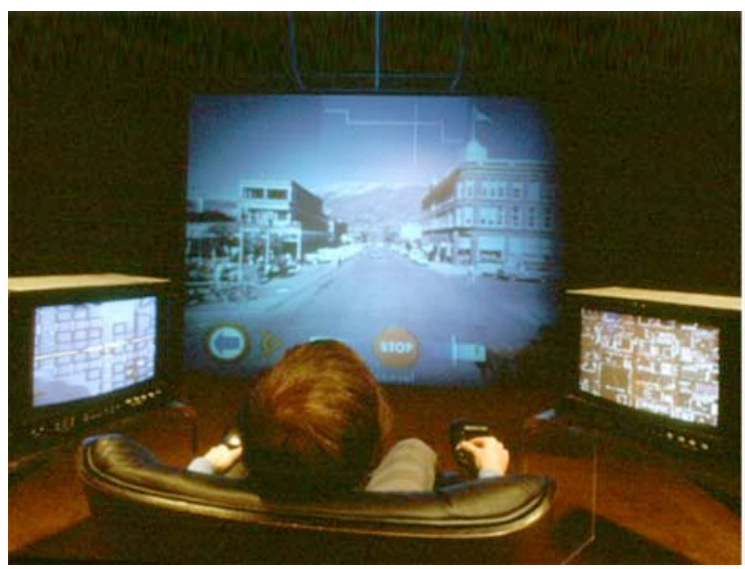

Fig. 1. The Aspen Moviemap, Architecture Machine Group, MIT, 1980

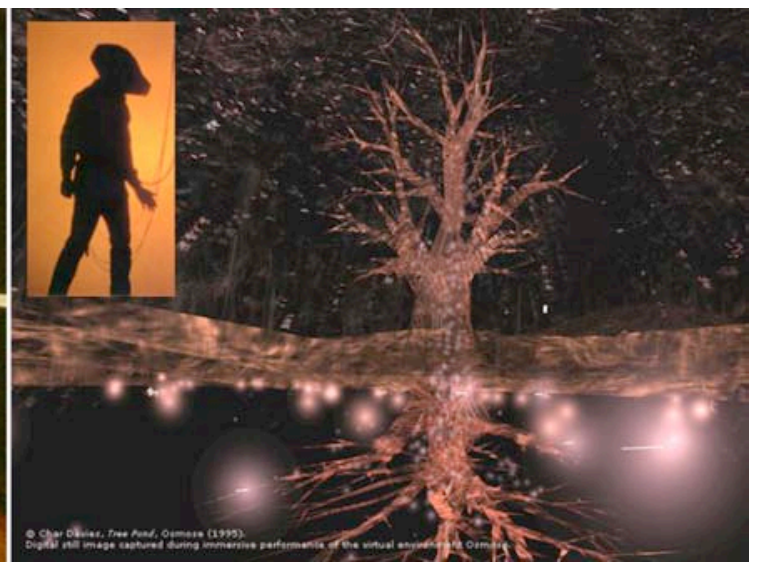

Fig. 2. Tree Pond, Osmose, Char Davies, Virtual Reality Installation, 1995.

Interactions with virtual spaces now lean towards an abandonment of encumbered experiences that depend upon awkward and expensive devises such as head-mounted displays and datagloves in favour of natural unencumbered interactions. Inspired by the knowledge that truthful psychological responses to virtual space are not dependent on realistic visuals and interaction, artists and computer scientists have explored alternate 
means of interaction. Although computer art such as web-art and online virtual worlds still depend on keyboard and mouse as primary input devices, artists have also capitalized on the technological development of inexpensive input/output circuit boards, sensors, switches, intuitive programming languages, and software applications. Before discussing computer art immersive spaces, it is important to reflect upon the changes in the traditional art that were taking place during this period.

\section{EARLY INSTALLATION ART}

While computer scientists and artists sought to create virtual spaces using the computer, traditional artists were abandoning the sterile white walls and rectangular pedestals of the gallery in favour of an activation of the space between the walls. Although experimental theatrical design works such as Kurt Schwitters' Merzbau (Fig. 3), which were constructed throughout his home in the 1920s through 1930s, received immediate recognition as the realization of a Gesamtkunstwerk, today we might look back and label the effort early installation artwork. [1] In the 1950s, artists such as Pollock, Allan Kaprow, James Rosenquist, and Claes Oldenburg began to obscure the line between the art object and its context, thus utilizing the space the work inhabits to enhance meaning. Poème Électronique, (Fig. 4) a collaborative work between Edgard Varèse, Le Corbusier, and Iannis Xenakis was exhibited at the 1958 Brussels World Fair and consisted of 400 loudspeakers, projected film, colored lights, and architecture. This seminal work was the first fully immersive environment that combined electronic music, projections, and architecture for the purpose of creating a total work of art. [14]

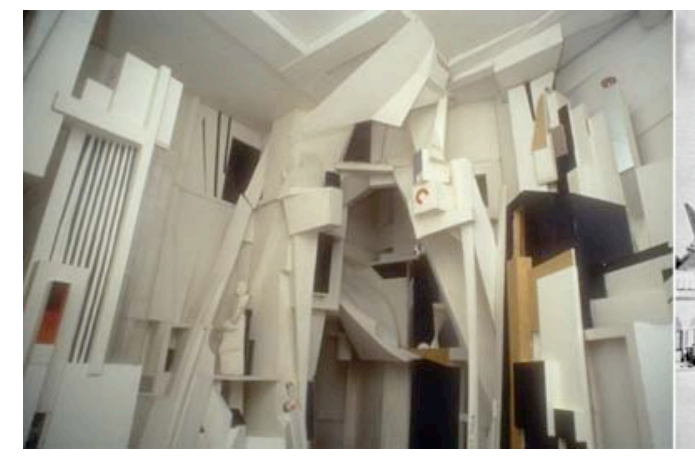

Fig. 3. Kurt Schwitters, Merzbau, 1924-37

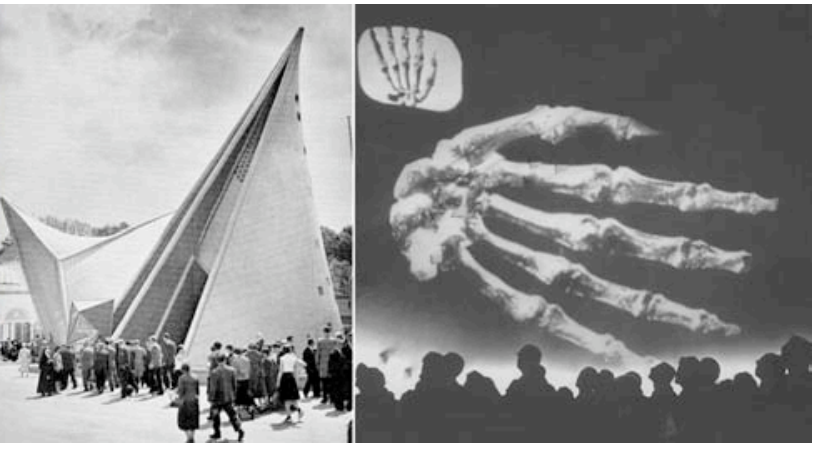

Fig. 4. The Philips Pavilion and Poème Électronique, Brussels World's Fair, 1958.

Since the 1960s, a new wave of artists have been transforming space into physical environments that defy realistic representation of recognizable environments. The physical space that these installation artworks inhabit often carries as much significance as the individual art object itself. The installation artist takes into account the viewer's entire sensory experience. The objects in an installation art space take on new meaning and the context of the elements defines the interpretation of the piece. Installation art often reflects and responds to the world we live in, thereby creating an interesting fusion of art and life. We must remember that the elements in the installation space are not art objects in themselves; the participant's experience is the work of art. Ronald J. Onorato in the book, Blurring the Boundaries: Installation Art 1969-1996, states, "The aesthetic power of installation art does not reside in a singular, commodified object but in an ability to become, rather than merely represent, the continuum of real experience by responding to specific situations." [8] 
Not surprisingly, by the 1970s we began to see installation artworks that seek to explore and satisfy the human desire to experience constructed realities. Artists incorporated film, video, performance, sound, objects, and architectural space to create complex aesthetic statements. In Organic Honey's Visual Telepathy, (Fig. 5) created in 1972, Joan Jonas created a virtual space using video and performance that visually represented the artist's alter ego (aptly named Organic Honey)'s imagination. [9] Video artists such as Nam June Paik created works such as TV Garden in 1974 (Fig. 6), that seamlessly integrated contemporary technology into an actual space populated with live plants. The convergence of the "real" (the plants) with the "virtual" (the illusionary space within the television screen) forced the viewer to accept these two decisively opposing forces as one unified element - the real and the virtual converge and become real in the end.

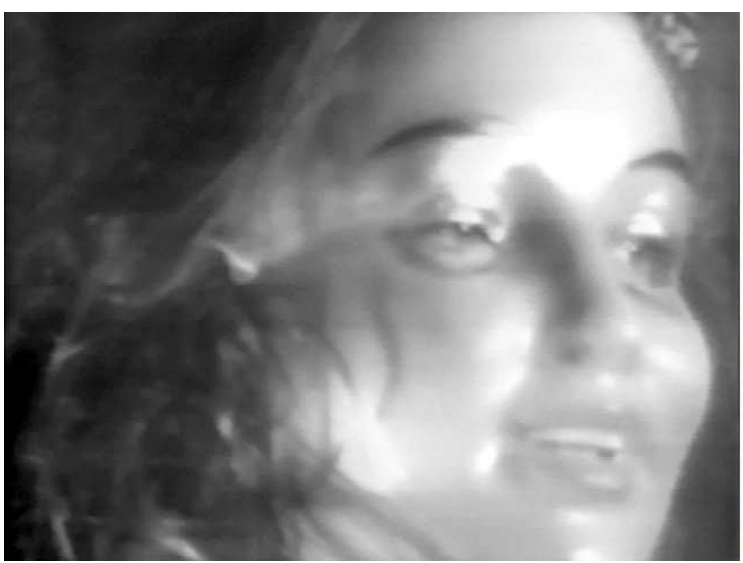

Fig. 5. Joan Jonas, Organic Honey's Visual Telepathy, Video Still from Performance, 1972

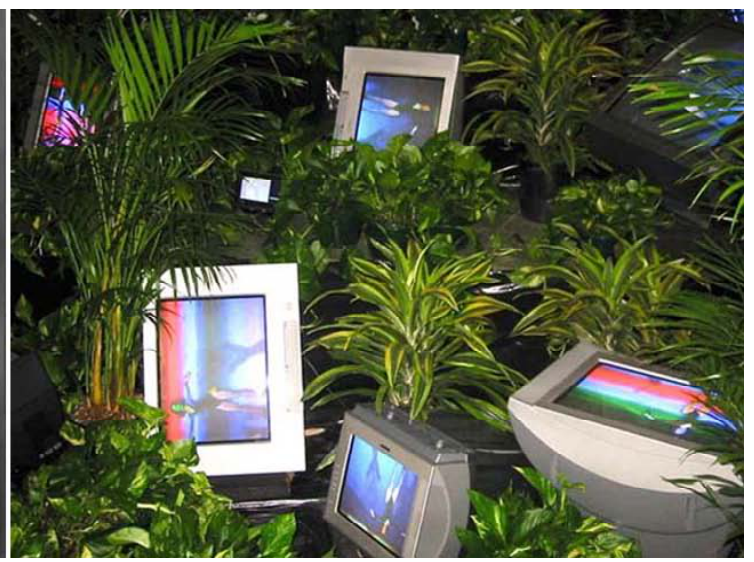

Fig. 6. Nam June Paik, TV Garden, 1974, Guggenheim Museum.

\section{CONVERGENCE}

As installation artists began incorporating digital technology into their work and computer artists began exploring the potential of physical environments united with virtual space, the goal of creating holodeck-type environments became superseded by desires to create spaces that capitalized on the best of both worlds. Electronic sensors, computer programming, digital audio, electronic moving and still images, and physical objects served as the basic building blocks enabling artists to create innovative works of art that used the human body as the interface. To create a convincing sense of immersion, a number of factors were considered. Participants entered into the space itself rather than view it from afar. The elements in the art environment filled the participant's peripheral vision creating the sensation of physical presence. Visual elements in the environment offered depth clues and moved accordingly. Multi-channel or ambisonic (three-dimensional) sound enabled participants to hear spatial relationships between themselves and the elements in the environment. The viewer often had a degree of interactive control over the unfolding of meaning in these innovative pieces. 


\section{VIRTUAL PRESENCE}

In 1992, Bonnie Mitchell explored the psychological effect of immersion in an installation entitled Virtual Presence, exhibited at the University of Oregon's Museum of Art. Viewers were invited into an enclosed semicircular room and were surrounded by computer monitors, each displaying a set of realistic eyes and a nose. The eyes blinked and rhythmic audio of breathing emanated from the computer. A Polaroid sonar sensor detected the distance of the viewer and responded by increasing the rate of breathing and visually altering the computer's face. Viewers in the environment were disturbed by the premise that the computers were living entities. Many viewers expressed the unpleasant sensation that they were being watched. This early immersive environment inspired a series of further installation works by the author.

\section{EXPERIENTIAL EXTREMISM}

In collaboration with electroacoustic composer, Elainie Lillios, Mitchell created an audio-visual interactive immersive installation artwork in 2005 for the International Computer Music Association Commission Award. Experiential Extremism (Fig. 7) explored the concept of extremism by focusing on enticements that cause people to gravitate toward thrill seeking and the emotional responses that occur before, during, and after extreme activities. By developing and manipulating abstract elements, they created an environment that evoked emotional and psychological responses similar to those that cause, maintain, or cease adrenaline rushes.
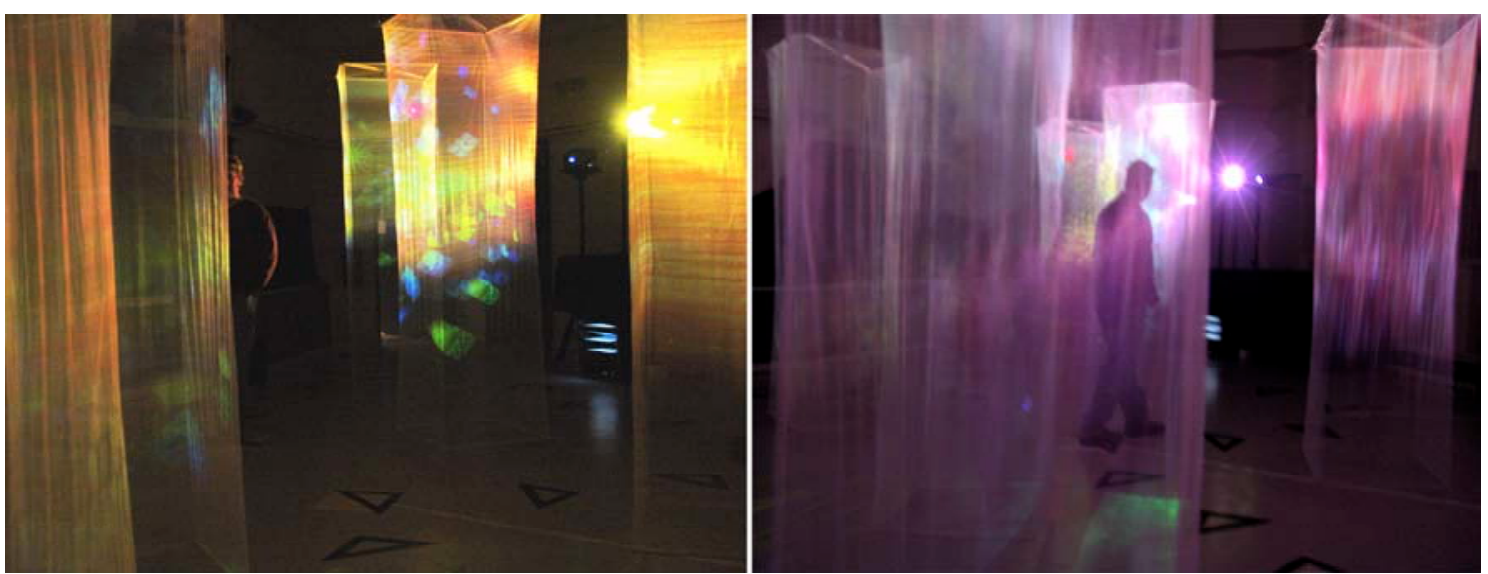

Fig. 7. Bonnie Mitchell \& Elainie Lillios, Experiential Extremism, 2005.

This immersive, interactive installation was divided into three physical areas, each representing one aspect of an extreme experience. Phase One, the "psych up" phase, mimicked psychological and emotional states of being prior to engaging in an extreme event. Phase Two, the "event" phase, abstractly portrayed the event itself. Phase Three, the "cool down" phase, represented post-experience reflection. Each phase evolved over time, and created a unique, individualized experience with each participant's visit. As an immersive installation, Experiential Extremism challenged and changed participants' perception of time and space, and provided an integrated, networked environment that transcended expectations of time-based, spatial art and sound.

\section{ENCOUNTER(S)}


In 2007, Lillios and Mitchell created Encounter(s), an interactive-immersive audio/visual environment (Fig. 8) that focused on the concepts of introspection, tranquillity and transformation. Each participant entered an immersive abstract sonic, animated world, and was enticed to sit in a centrally located seat. When the participant sat down, they triggered the emergence of a distant, abstracted ethereal figure that slowly moved towards the participant. When the figure arrived in front of the participant, it asked an introspective question. After a moment of contemplation, the figure retreated into the distance and transformed into a tree-like form that metaphorically represented self-actualization and growth.

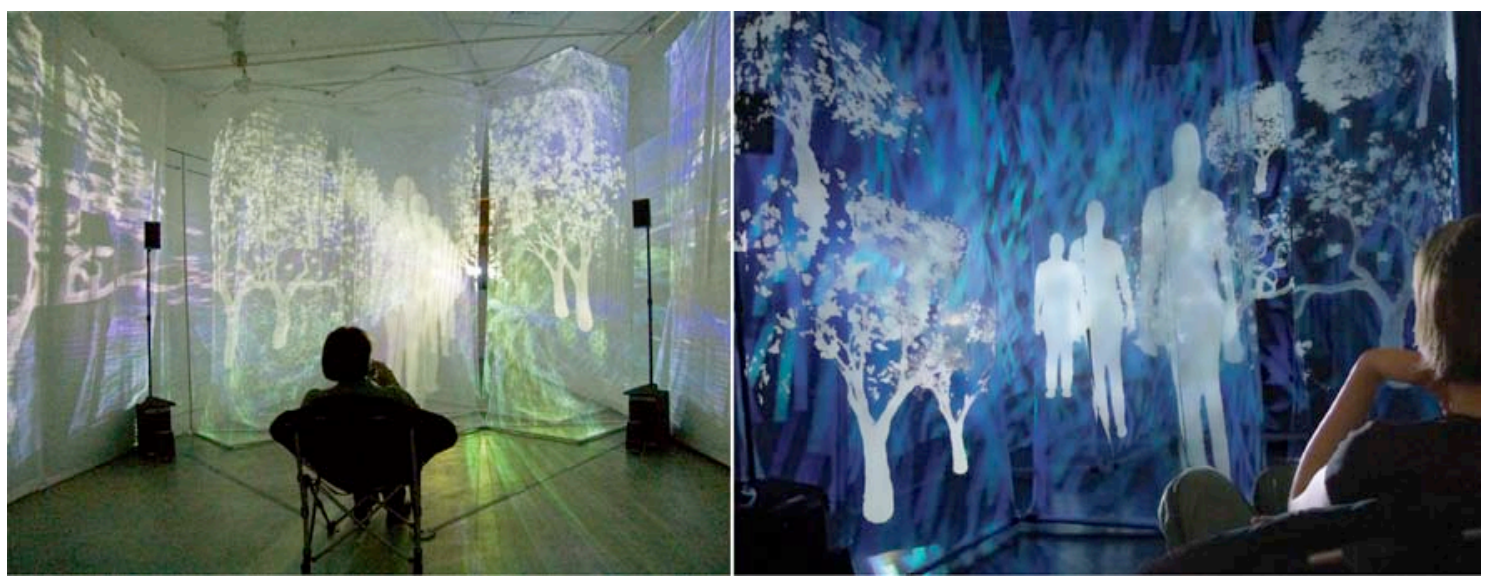

Fig. 8. Bonnie Mitchell \& Elainie Lillios, Encounter(s), 2007.

Eight loudspeakers and four subwoofers were arranged to create a full spherical (periphonic) listening environment using Ambisonics, a three-dimensional audio encoding/decoding system. Custom-designed, fabric walls suspended from the ceiling, defined the installation's physical space. These fabric walls also echoed the animations on all sides of the participant, filling the peripheral vision.

\section{SOCIAL INTERACTION}

Although spectators were able to view the participant in the centre, Encounter $(s)$ was designed as a solitary experience. Although Experiential Extremism facilitated up to 20 visitors at a time, neither installation encouraged nor facilitated group interaction. Because of the popularity of online multi-user games, Facebook, Twitter and other social networks, it is evident that human beings crave interaction with other human beings. Computer-facilitated communication often satisfies the desire to connect with others even though the experience is often not immersive and does not attempt to replicate realistic communicative environments. When spatial immersion and interaction is coupled with human-to-human interaction via avatars, voice, or text the level of active engagement increases substantially. Online virtual worlds such as World of Warcraft and Second Life boast over 11 million subscribers and 16 million accounts respectively. Second Life is entirely user-created and the environments are easily manipulated, therefore very conducive as an art medium.

\section{ART IN SECOND LIFE}

Second Life is a 'multi-user virtual environment' (MUVE) in which users of an online $3 \mathrm{~d}$ space interact through avatars using voice and text chat. Also called 'Residents', 
users can explore, meet other Residents, socialize, participate in individual and group activities, as well as create and trade virtual items and services. Second Life offers artists an interactive online social environment that can be sculpted using computer programming and the construction of virtual $3 \mathrm{~d}$ objects.

Aesthetic responses are typically enhanced by encoding experiences visually and sonically as well as adding a participatory component. Through the development of algorithms, environments can be created that respond to avatars and change over time. Artists such as Juria Yoshikawa and Dan Coyote as well as many others, have created art experiences that fully engage the senses through the marriage of sonic and visual effects coupled with immersion and social interaction.

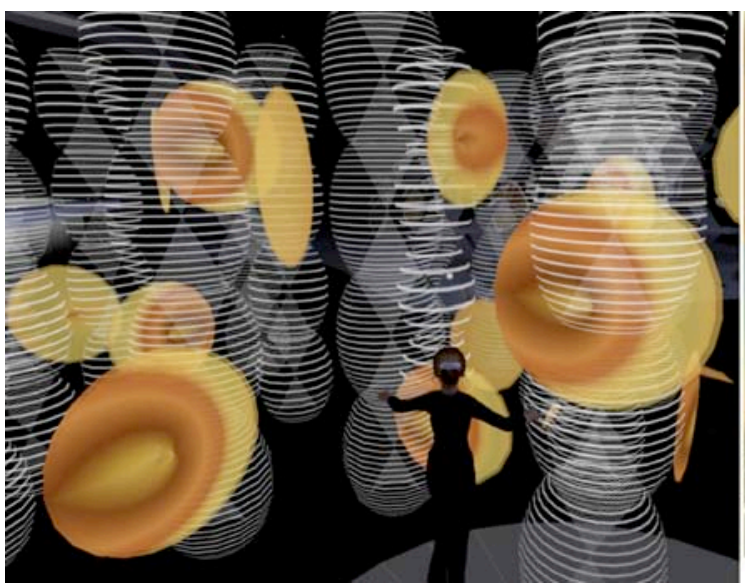

Fig. 9. Juria Yoshikawa,

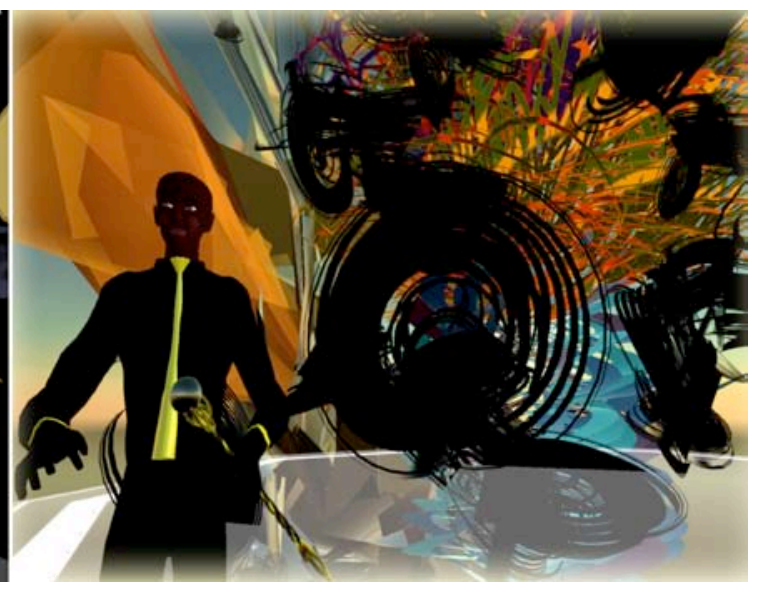

Fig. 10. DanCoyote Antonelli.

Juria Yoshikawa, also known as Lance Shields in real-life, is interested in phenomenology in the virtual world, or the reflective study of the essence of consciousness as experienced from a first person point of view. Although Lance is a male artist living in Tokyo in the real world, the works in Second Life are all created by one of his alter egos, an avatar called Juria, a female. Juria uses the elements in Second Life and the Linden Scripting Language to create works that are impossible to make in the real world (Fig. 9). She mixes kinetic objects, animated textures, ambient noise and animations to create social experiences that are multi-sensory and immersive. The works are typically large in scale thus encouraging avatars to fly through and interact with the work in non-traditional ways. [11]

DanCoyote Antonelli, also known as DC Spensley in real life, has created a number of art works under the genre he calls Hyperformalism. The first generation of works he created was paintings and digital art uploaded into Second Life. The second generation was art made only from the Second Life default inventory materials (Fig. 10) and the third generation was a synthesis of the first two, combined with scripting in Second Life. Hyperformalism is described by Antonelli as "an aesthetic philosophical construct that may be employed to describe a late 20 th century, early 21 st century mass art phenomena consisting of scores of personal computer users generating abstract, often spatially unique artworks with software tools. These spatial realities have no analog in the physical world, and instead of making reference to physical reality, create a unique continuum of reference; a rearrangement of photons to illuminate alternate worlds of 
form, shape, color and space." [12] Although Second Life facilitates the development of artworks that can only be made in the virtual world, it is inhabited by avatars controlled by real people. Social interaction facilitated by the virtual environment as well as the layered fabric of identity inherent in avatar cultures, makes online experiences such as Second Life ripe with possibilities for artistic exploration.

\section{CONCLUSION}

Through the definition, creation, and manipulation of both virtual and physical space, computer artists have created powerful aesthetic environments that enable audiences to experience alternative realities. The original quest to create virtual spaces that mimic terrestrial space and real world interaction has not fallen to the wayside solely because of technical limitations. Encumbered artificial reality experiences have proven to be expensive, intrusive, and often interfere with natural sensory perception. Immersive installations that respond the human body and online multi-user virtual environments such as Second Life satisfy the viewer's inherent desire to escape physical reality and become part of the art experience itself. Technological advances and shifting art practices have expanded the palette of the computer artist over the past fifty years and promise to radically alter computer artist's exploitation of space in the future.

\section{References}

[1] ARCHER, MICHAEL: Installation Art. 1994 Thames and Hudson Ltd, London. Pg 18.

[2] BRADBURY, RAY: The Illustrated Man. 1951 Doubleday Press, Garden City. The Veldt.

[3] CACHe Archives - History http://www.e-x-p.org/cache/history.htm.

[4] DAVIES, CHAR: Changing Space: Virtual Reality as an Arena of Embodied Being (1997). Multimedia from Wagner to Virtual Reality by Randall Packer and Ken Jordan. 2001 W. W. Norton and Company, New York.

[5] FISCHER, SCOTT S: Virtual Interface Environments. In The Art of HumanComputer Interface Design, by Brenda Laurel. 1990 Addison-Wesley Publishing Co.

[6] HEIM, MICHAEL: The Metaphysics of Virtual Reality. 1993 Oxford University Press, NY. Pgs. 129-130.

[7] KRUGER, MYRON K: Artificial Reality 2. 1991 Addison-Wesley, Reading, Massachusetts.

[8] ONORATO, RONALD J: Blurring the Boundaries: Installation Art 1969-1996. 1997 Marquand Books, Inc., Seattle. Pg 13. 
[9] RUSH, MICHAEL: New Media in Late 20 ${ }^{\text {th }}$-Century Art. 1999 Thames and Hudson, London. Pgs. 41-43.

[10] Star Trek: The Animated Series, http://en.wikipedia.org/wiki/Star Trek: The Animated Series

[11] The SL Art of Yoshikawa, Juria http://juriayoshikawa.blogspot.com/

[12] SPENSLEY, DC: Hyperformalism: A theoretical construct by network neologist.

http://spensley.com/hyperformalism/index1.html

[13] SUTHERLAND, I. G: A head-mounted three-dimensional display. 1968 Proceeding of the Fall Joint Computer Conference. AFIPS Conference Proceedings, vol. 33, Arlington, VA, 757- 764

[14] VARÈSE, EDGARD: Poéme Èlectronique. 1958 Notes Presented at the Concert http://music.columbia.edu/masterpieces/notes/varese/notes.html

[15] WARDRIP-FRUIN, NOAH and Montfort: The NewMediaReader, Chapter 25, Responsive Environments. 2003 MIT Press, Boston, Massachusetts. 